\title{
Jean Leclerc (éd.), L'antiquité travestie: anthologie de poésie burlesque (1644-1658)
}

Laura Rescia

\section{(2) OpenEdition}

\section{Journals}

\section{Edizione digitale}

URL: https://journals.openedition.org/studifrancesi/4661

DOI: 10.4000/studifrancesi.4661

ISSN: 2421-5856

\section{Editore}

Rosenberg \& Sellier

\section{Edizione cartacea}

Data di pubblicazione: 1 avril 2012

Paginazione: 140

ISSN: 0039-2944

\section{Notizia bibliografica digitale}

Laura Rescia, «Jean Leclerc (éd.), L'antiquité travestie: anthologie de poésie burlesque (1644-1658)», Studi Francesi [Online], 166 (I | LVI) | 2012, online dal 30 novembre 2015, consultato il 19 novembre 2021. URL: http://journals.openedition.org/studifrancesi/4661 ; DOI: https://doi.org/10.4000/studifrancesi. 4661

Questo documento è stato generato automaticamente il 19 novembre 2021.

\section{(c) $(1)$}

Studi Francesi è distribuita con Licenza Creative Commons Attribuzione - Non commerciale - Non opere derivate 4.0 Internazionale. 


\title{
Jean Leclerc (éd.), L'antiquité travestie: anthologie de poésie burlesque (1644-1658)
}

\author{
Laura Rescia
}

\section{NOTIZIA}

JEAN LECLERC (éd.), L'antiquité travestie: anthologie de poésie burlesque (1644-1658), Québec, Editions du CIERL - Presses de l'Université Laval, 2010, pp. 549.

1 Il volume raccoglie dieci opere, tratte da un corpus di poesie burlesche pubblicate sotto la reggenza di Anna d'Austria, di cui sei nel periodo della Fronda, alcune delle quali inedite, altre non più pubblicate negli ultimi cinquant'anni. Si tratta di un sottogenere della poesia burlesca, quello del travestissement en vers burlesques che, come noto, pratica la riscrittura di grandi testi dell'antichità, rendendo riconoscibile il modello ma modificandone lo stile. Fortemente influenzati dal Virgile travesti di Scarron, ma anche dalle mazarinades, questi testi testimoniano il gusto per il rinnovamento dei modelli antichi e per la fantasia linguistica. Di estremo interesse non solo per la storia letteraria, ma altresì per la storia della lingua, essi vengono presentati in una buona edizione, in cui viene rispettata l'ortografia dell'epoca e riprodotte le pièces liminaires. Ogni testo viene introdotto da un cappello relativo all'autore, all'editore e al dedicatario, da una notizia relativa all'edizione di riferimento e ai criteri di trascrizione, seguita da una sinossi analitica del poema. Le varianti vengono riportate al termine del volume, chiuso da un ricco glossario (suddiviso in due rubriche che separano le unità sintagmatiche semplici dalle locuzioni), un indice dei nomi e una bibliografia, nella quale spicca il vasto utilizzo di trattati coevi indispensabili per la comprensione del lessico di specialità (culinario, farmaceutico). L'annotazione dei testi è utile per quanto sintetica. Vengono altresì riportate tre traduzioni dell'epoca (il libro XII delle Metamorfosi ovidiane tradotte da N. Renouard, il Farsalo di Lucano, libro I, 
tradotto da G. Brébeuf, e la prima satira di Giovenale tradotta da M. de Marolles) affinché il lettore possa meglio valutare lo scarto tra traduzione e riscrittura burlesca. 